\title{
Analysis of the model of integration of multicultural media in the network's space of public opinion
}

\author{
Análise do modelo de integração de mídias multiculturais \\ no espaço de opinião pública da rede
}

\author{
Liang WANG 1 (D) 0000-0003-0085-7955 \\ Chen DONG ${ }^{2}$ (iD) 0000-0001-8044-4995
}

\begin{abstract}
When the traditional Meta database model is used to integrate multicultural media in the network's space of public opinion, the performance of cooperative processing of distributed heterogeneous network data is poor, the logic of integration of multicultural media information is poor, the integration time is long, and the accuracy is low. This article proposes a multicultural media integration model based on multi-agent collaboration, which combines the life cycle of multicultural media models in the network's space of public opinion. In distributed heterogeneous network spaces of public opinion, data is obtained from the distributed multicultural media information source, transferred to the multi-agent, and the collaboration among the agents is constructed. The multicultural media integration model provides the work flow and the standard principle of the model, and shapes the integrated model's architecture including the data layer, the middle layer, and the expression layer, so as to achieve the intelligent integration of the multicultural media information. The experimental results show that the proposed model has high practicability, high integration efficiency and accuracy, and can enhance the penetration of multicultural media brands.
\end{abstract}

Keywords: Distributed heterogeneity. Information integration. Multiculturalism. Network environment. Public opinion.

\section{Resumo}

Quando o modelo tradicional de banco de dados Meta é usado para integrar mídia multicultural no espaço de opinião pública da rede, o desempenho do processamento cooperativo de dados de rede heterogêneos distribuídos é ruim, a lógica da integração das informações da mídia multicultural é ruim e o tempo de integração é longo e a precisão é baixa. Esse artigo propõe o modelo de integração de mídia multicultural com base na colaboração de vários agentes, que combina o ciclo de vida do modelo de mídia multicultural no espaço de opinião pública da rede. No espaço de opinião pública da rede heterogênea distribuída, os dados são obtidos da fonte de informação de mídia multicultural distribuída, os dados são transferidos para o multiagente e a colaboração entre vários agentes é construída. O modelo de integração de mídia multicultural fornece o fluxo de trabalho e o princípio padrão do modelo molda a arquitetura do modelo integrado, incluindo a camada de dados, a camada do meio e a camada de expressão, de modo a realizar a integração inteligente das informações da mídia multicultural. Os resultados experimentais mostram que o modelo proposto possui alta praticabilidade, alta eficiência e precisão de integração e pode aumentar a penetração de marcas de mídia multicultural.

Palavras-chave: Heterogeneidade distribuída. Integração de informação. Multiculturalismo. Ambiente de rede. Opinião pública.

1 Shandong Sport University, School of Sport Social Science, Sports Economy and Management Office. Shiji Road, Jinan, China.

2 Shandong Sport University, School of Sport Social Science, Health Service and Management Office. Shiji Road, Jinan, China. Correspondência para/Correspondence to: C. DONG. E-mail: <dcspt1988@126.com>.

Support: National Social Science Fund of China (n० 18ATY002), Foundation for the Excellent Youth Scholars of Shandong Educational Committee $\left(n^{\circ} 72\right)$.

Received on July 9, 2020, final version resubmitted on October 23, 2020 and approved on October 28, 2020.

Como citar este artigo/How to cite this article

Wang, L.; Dong, C. Analysis of the model of integration of multicultural media in the network's space of public opinion. Transinformação, v. 32, e200044, 2020. https://doi.org/10.1590/2318-0889202032e200044 


\section{Introduction}

Since the beginning of the twenty-first century, the Internet connects the whole world as a representative of multicultural media, and information dissemination shows the characteristics of globalization and pluralism. Network multicultural media can bring great freedom of information but it may also lead to a series of social conflicts. Whether these conflicts' are inevitable or not, multicultural media is often regarded as a major force driving their outbreaks. The main reason for it is that the network is a form of endpoint media which provides the individual with relatively low-cost, independent, which provides a material basis for the diversification of information dissemination (Liu, 2018; Zhang; Lu, 2018). But we also have to pay attention to the social risks brought by this mode of diversified information dissemination (Guo et al., 2019; Liu; Zhao, 2019; Zhang et al., 2019). On the internet, because of its wide spread, users interact frequently on it, creating a multicultural ideological field. In order to adapt to the fast-changing network of spaces of public opinion, the integration of multicultural media is particularly important (Hooghe; Vroome, 2015). When the traditional Meta database model is integrated with multicultural media in the network's space of public opinion, the performance of the cooperative processing of distributed heterogeneous network data is poor and the logic of integration of multicultural media information is poor (He et al., 2019; Sun; Xu; Jiang, 2019; Zeng et al., 2019; Sun et al., 2020), which consumes a long time and has low precision. Therefore, this paper proposes a new model of integration of multicultural media in the network spaces to achieve the intelligent integration of multicultural media in the distributed heterogeneous network spaces.

\section{Analysis of the model of integration of multicultural media in the network's space of public opinion}

\section{Formation of the multicultural media model}

According to a basic definition, "culture" is, first of all, a way of life. For Internet users, their network activities are a digital lifestyle rooted in the network's spaces of public opinion. Conversely, this digital lifestyle has also constructed and presented multicultural media. Multicultural media is not only the product of Internet users, but also their life. Therefore, the formation of multicultural media in the network's spaces of public opinion comes from the common influence and interaction of two aspects: one is the communication characteristic of the network and the other is the network activity mode of Internet users. These features interact with each other and create a variety of network multicultural media with diverse forms and complex content through specific network practices.

The propagation characteristics of multicultural media in the network's spaces of public opinion provide the basis for the formation of the network multimedia model. The anonymity, randomness, publicity, and the shortcuts of the network multicultural media make it possible for Internet users to maximize their effect by using the least amount of resources possible in the production processes of the text in the network's spaces of public opinion (Vazquez, 2014). By creating, sharing, and preserving these three basic network activities, Internet users produce and reproduce network media, such as symbols, audio, video, and images, so as to build new meanings and understandings taken as self-evident. The access to the right to speak, attract the eye, guide public opinion, create topics, lead the trend, and influence all aspects of social life through the process of adaptive construction, thus forming a kind of social lifestyle of multicultural media in the network's space of public opinion, are also very important (Hwang, 2016).

The combination of the characteristics of network multicultural media dissemination and Internet users' activities has created a complex and diverse network of multicultural media in China at present. In the public 
opinion space of Chinese Internet, there are many popular words, which vividly and concisely express public sentiment and spread widely. Through the process of production and reproduction of texts into people's daily life, a type of fact has been formed. In social life, a large number of people produce and consume multiculturalism. The people is no longer satisfied with the values offered by the mainstream ideology and is willing to invest more resources to consume and disseminate the various values that come from the network media.

The main reason is that the network's space of public opinion has a powerful and modern ability of cultural construction. From this point of view, the scene of network multicultural media is the performance of modern cultural thought and practice in the network field (Ahmed; Veronis, 2017). It can integrate people in different cultural contexts with the same coding and decoding mechanism and form a single culture of public opinion. The reproduction of various real-world opinions through the network has not only lost touch with reality, but also turn into a multicultural media field with fiction, sense, consumption, and diversity. As the landmark media of the modern society, the network dispels the unique historical traditions, cultural connotations, and life experiences of various ethnic groups on various means of communication, but the national traditional culture is replaced by the multicultural media field of virtual construction Accordingly, the liberalization, arbitrariness, and virtualization of the subjective constructivist media are historic and cultural logics, which essentially abolished the historic and cultural logics of the construction of the human body (Lauridsen, 2016). Therefore, in the network's spaces of public opinion, the great expansion of multiculturalism drive people in the specific historic and cultural context and the specific national country to enjoy the fanaticism in this multicultural media model, which essentially dispels the problem of coding and decoding caused by the communication of culture. It makes people pursue the use of various multimedia to convey culture, but does not pursue the understanding of the essence of conveying information.

\section{The integration mechanism of multicultural media model}

China has become a society with multicultural media on the Internet, which is an established fact. The analysis above shows that when China became a society of network multicultural media, an established fact, the Chinese society entered a period of social transformation, and the multicultural society brought high risk, much friction, and strong conflicts. Especially for the people born in the 1970s-90s, the multimedia environment of the Internet is one of the most important growing environments. A lot of young cultural organizations and groups are growing because of the influence of the Internet media. On the other hand, the pressure and labor pains brought by the spread of multicultural media in the whole society are intensifying (Titley, 2014). The friction between the network multicultural media and the mainstream social culture is increasingly intense, and the conflict between the network's spaces of public opinion and real society is increasingly obvious. All societies will face more and more systemic risks and pressures, and the multi-layer cultural contradiction will increase the difficulty of integrating multicultural media. Therefore, it is necessary to have a multicultural media management organization that can reconcile the conflicts between cultures, so as to adjust the peaceful atmosphere of society.

Figure 1 shows that the model of integration of multicultural media in the online spaces of public opinion mainly includes three parts: the information flow collection layer, the information flow application layer, and the multicultural media integration layer. The information flow collection layer is the collection part of the multicultural media in the network's space of public opinion in the system. Its interface is used to effectively collect various types of multicultural media in the network's space of public opinion. The multicultural media integration layer will categorize the collected multicultural media. After the classification, it is sent to the multicultural media indexing module, which uses the constraint logic planning method to effectively index the classified information. The classification in the system and the information flow after indexing are sent simultaneously to the corresponding database. The post-information flow uses the four parts of information flow (update, search, binding, and call) to carry out the integration of multicultural media in the network's spaces of public opinion through the management 
model of multicultural media in the online spaces of public opinion. A fault-tolerant mechanism is set up in the system to restore faulty nodes in it and improve the reliability of multicultural media integration. The integration results provide users with integrated services through the information flow application layer interface. The integration model of multicultural media in the online spaces of public opinion carries out the data integration and processing of multicultural media within it, and enhances the individualization, intelligence, and optimization of its integration.

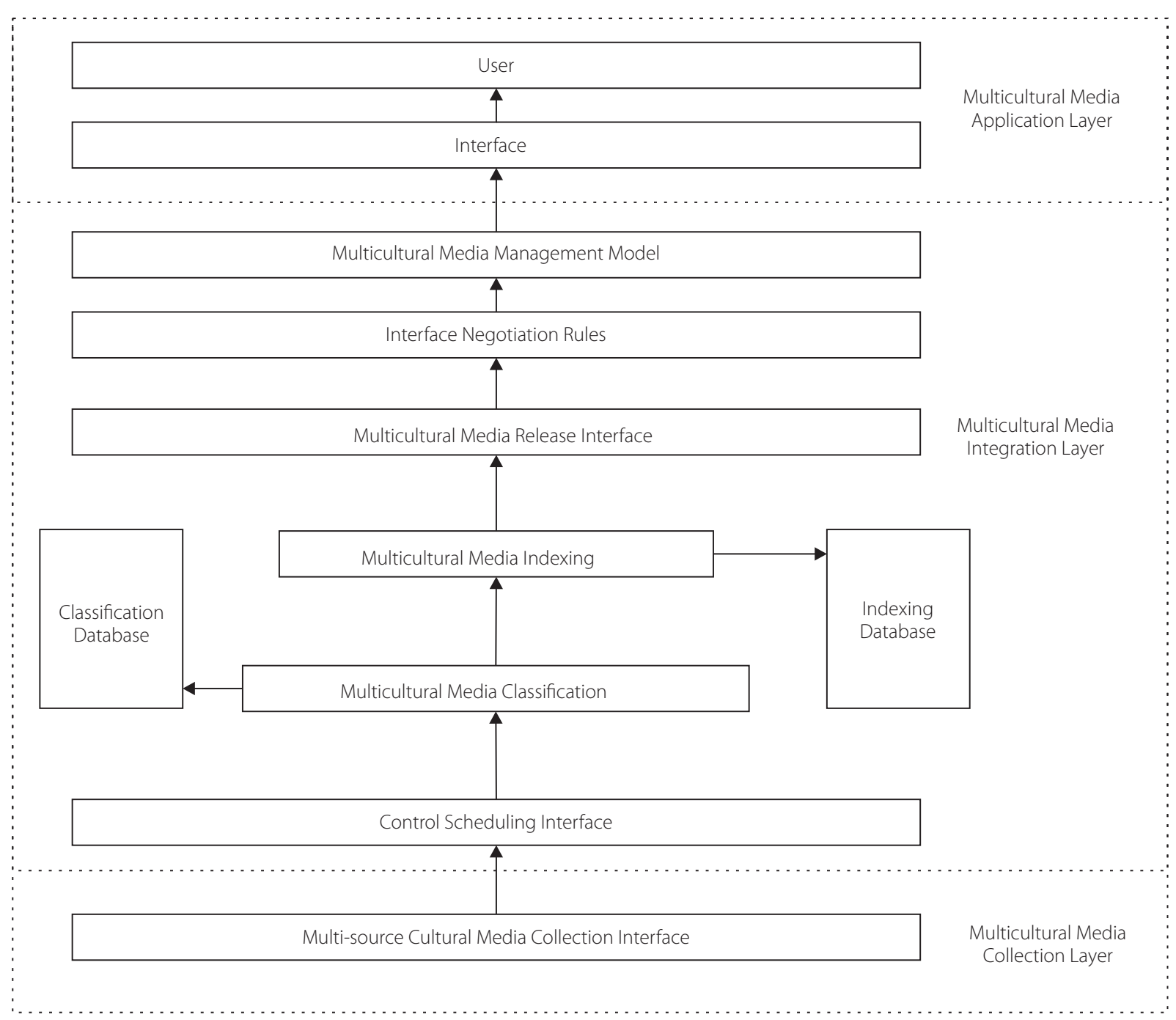

Figure 1. General structure of the integration model of multicultural media in the network's spacse of public opinion. Source: Elaborated by authors (2019).

For this reason, this paper defends that only from three basic links can one build a model mechanism of multicultural media integration:

(1) While advocating the mainstream cultural values, we should also establish a multicultural media inclusion mechanism. Multicultural media inclusiveness is relatively lacking in China's cultural ecology environment. Regardless of the governance system, the regulatory mechanism, or the government organization, they are not ready for the change of multicultural media. This is clearly in conflict with the current multicultural media status. In 
the future, with the advancement of the adaptive construction process, more and more conflicts will erupt between the multicultural media and the mainstream culture in the network's spaces of public opinion, increasingly affecting people's ability to manage and reform the government (Ahmed; Veronis, 2016). The suspicion related to political credibility does not exclude that social contradictions may be intensified under certain conditions.

(2) To implement a multicultural media convergence policy while combating extremism. Whether it is the multicultural media in the network's spaces of public opinion or the media in real society, its formation is rooted in the economic foundation and structure of the huge changes. The regulator can only provide a loose platform for the expression, appeal, and display of the multicultural media, which may promote its benign development. However, it is undeniable that the multicultural media of group life form is the soil for some extremist trends of thought. The British Prime Minister, for example, acknowledged the risk of failure in the British multicultural media integration policy for the next years, given that extremist cultural ideas are on the rise in Britain. Therefore, implementing the policy of multicultural media convergence is an important governance step to fight and dismantle extremism.

(3) To build multicultural media law and make adjustments based on changing times. It is generally believed that the implementation of multicultural media law helps form a social atmosphere of tolerance and understanding of different cultures. Many contradictions and disputes arising from national cultural differences will be alleviated and solved. However, whether our legal system can adapt to the multicultural media, it is still up for grabs.

\section{Life cycle of multicultural media models in the network's spaces of public opinion}

In the network's spaces of public opinion, any hot topic of cultural media experiences a process of existence and disappearance. The evolution and development of the multicultural media model conforms to the periodic law of the period of public opinion, outbreak, and elimination. As shown in Supplementary data 1 (Wang; Dong, 2020), the life cycle of multimedia models in network's space of public opinion has universality and particularity. Its universality lies in the periodicity of the occurrence and evolution of multicultural media models.

Multicultural media models are unbalanced in all life stages. That is, the period of formation of public opinion is relatively short, its growth and maturity periods are longer, and the decline period is temporary. Multicultural media increase information in the process of communication to promote continued wide dissemination. Whenever new information comes in, the intensity of information stimulation will increase and the transmission of media events will peak for a time and then slide slowly. If there is no new information to make up for it, it will gradually decay.

Multicultural media models are linked by various lifecycles. New media hot spots are constantly emerging and will compete with the old ones. The emergence of new issues will promote the decay of old issues. The mass of Internet opinion information causes new hot spots to emerge constantly. It will surely divert people's attention and attenuate the attention given to old topics.

Rumor, as the element of butterfly effect in the multicultural media model, has some special characteristics in its life cycle. In the network's spaces of public opinion, because of the increase of source and the weakening of gatekeepers, the network topology structure has also prepared a channel for the spread of rumors. The cost of production and dissemination of false media information is reduced, and the efficiency of communication is improved. All kinds of subjective assumptions and conjectures can be found in public spaces of opinion without examination (Fleras, 2015). This directly leads to rumors forming a circular chain in the butterfly effect of the multicultural media model. In a word, life cycle theory has a special guiding significance in explaining the butterfly effect of multicultural media model. The chain reaction concept of butterfly effect theory also provides a feasible perspective to explain the evolution of multicultural media model. 


\section{Constructing a multicultural media integration model based on multi-agent collaboration}

Facing the massive information brought by multicultural media resources, common retrieval tools often retrieve a large number of uneven and unstructured data, most of which do not meet the needs of the users. Therefore, it is necessary to integrate a wide range of multicultural media models in the network's spaces of public opinion. Standardization is convenient for a large number of users to browse and use.

The integration of multicultural media models in distributed heterogeneous network public opinion environments requires data obtained from distributed information sources. The integration model should be adaptive and intelligent. Because the agent has the characteristics of autonomy, interaction, and reactivity, this paper obtains data from distributed multicultural media information sources in distributed heterogeneous network spaces of public opinion, transfers data to multi-agent, and constructs a multi-agent integration model based on multi-agent cooperation.

\section{Model workflow}

(1) The user proposes the retrieval request; the user interface agent responds, calls the user's customary knowledge base, creates a personalized interface that meets the user's needs, and guides the user to complete the construction of the retrieval type (Jara-Ibarra, 2014).

(2) The reasoning agent will start to deduce the user's implicit retrieval requirements, merge explicit and implicit retrieval requests, standardize the retrieval request after processing, and submit it to the search agent.

(3) Each search agent translates the normalized search request into a format corresponding to the requirements of the engine, starts the engine's search, and the multi-member search engine carries out the parallel retrieval of heterogeneous multicultural media information sources.

(4) It integrates agents to process, retrieve, merge, and sort the retrieval results of independent search engines, and returns them to knowledge agents.

(5) The knowledge agent refers to the user's customary knowledge base, filters out the results of the multicultural media information that do not meet the requirements of the personalization, and makes a general survey of the related results into knowledge together with the list of URL, and returns the media user interface agent (Bolstad, 2016).

(6) The media user interface agent presents the results of the multicultural media information integration to users and accepts feedback from them.

(7) The agent updates the user's familiar knowledge base according to user's feedback information.

\section{The norm principle of the model}

(1) The principle of integrity is intended to maintain the integrity of the subject of the digital resource object. The integrated multicultural media model should cover the internal functions of the subsystems and reflect the internal relations among the data objects.

(2) The principle of targeting, also called the principle of individuation, refers to the purpose of integration of multicultural media models. After integrating the multimedia model, digital resources should meet the needs of specific users.

(3) The hierarchical principle refers to the structure of the multicultural media integration model, the multicultural media itself, and the hierarchy of user needs, and it requires multi-dimensional integration according to various types, layers, and ways.

(4) The scientific principle refers to the scientific argumentation of objects, contents, and ways of the integration model of multicultural media, and should not be arbitrarily integrated. 
(5) The principle of optimization refers to the use of certain technical means and methods to make a rational combination of the integrated model of multicultural media and obtains the best organizational structure and organizational function.

(6) The principle of dynamics, also known as the principle of openness, means that the multicultural media integration model system is a developing system. It is not permanent, but closely related to multicultural media resource environment, network public opinion space and user demand, and drives the change of network public opinion space environment. It shows the openness and evolution of the overall function of the multimedia integration model (Barzilay; Urquhart, 2014).

\section{Model architecture setting}

According to the function and integration principle of the multicultural media integration model in the network's space of public opinion, this paper designs the architecture of a multicultural media integration model based on multi-agent collaboration (Figure 2). On Figure 2, we can see that this multicultural media integration model can be integrated on three layers, which are the data layer, the middle layer, and the presentation layer.

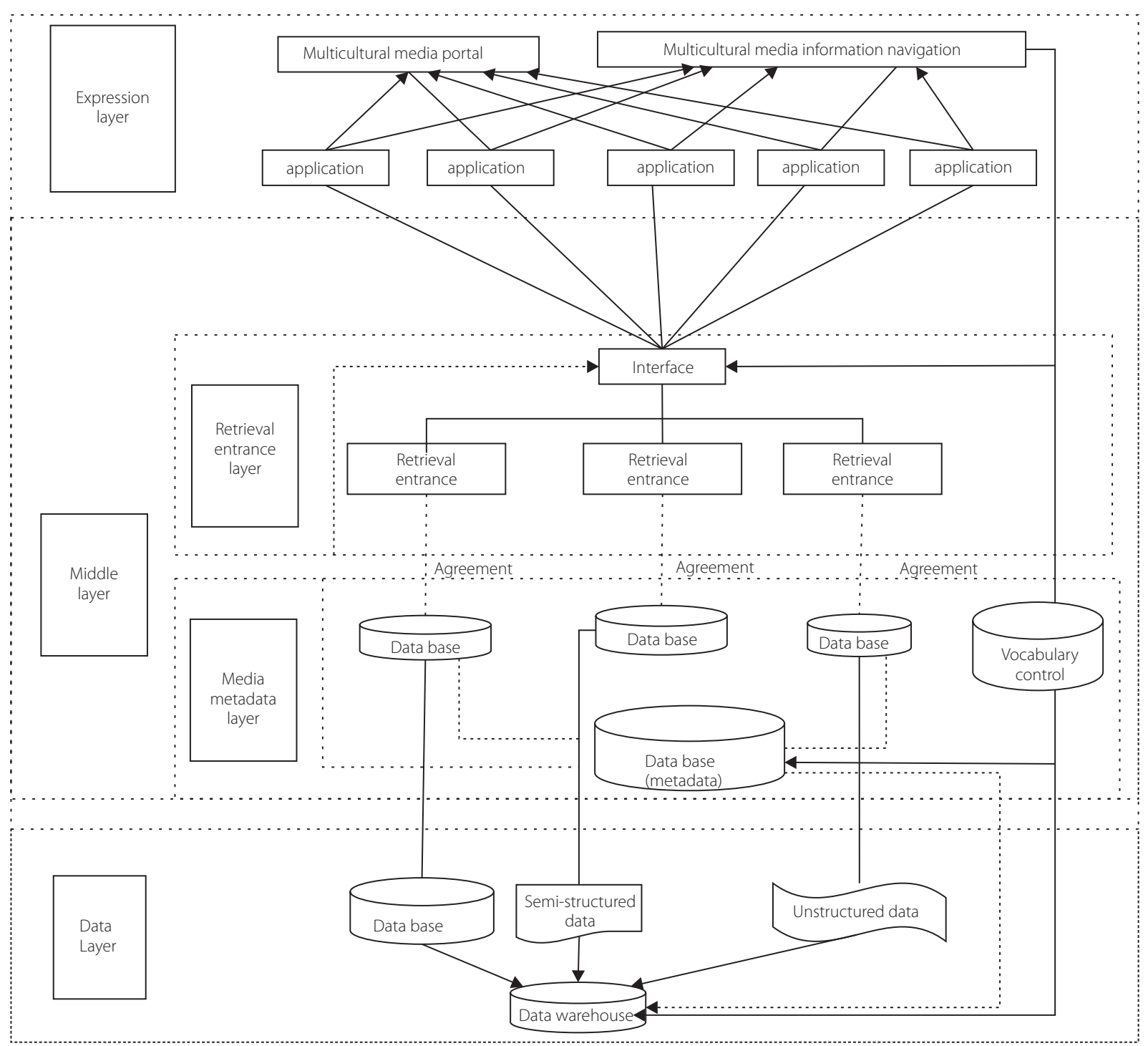

Figure 2. The architecture of the multimedia integration model in the network's spaces of public opinion.

Source: Elaborated by authors (2019). 


\section{Data layer integration}

The data layer is also the basic layer. The multicultural media integration model's data layer is a physical integration method, which is a method of media integration under the guidance of the large concentration of multicultural media data. Date layer integration is the process of re organizing, deep processing, and knowledge service of existing multicultural media information resources. It needs to build a new storage repository to load the various media resources that are collected. The media information resources of different structures are organized into the same data format, and all the multicultural media information resources are easily retrieved with a unified retrieval platform (Deutschmann; Minkus, 2018). The advantage of data layer integration is that after it is done, it is easy to carry out the unified storage or migration of multicultural media data so as to facilitate data mining, analysis, and decision-making based on it.

\section{Interlayer integration}

Intermediate layer integration is a logical (or virtual) integration method, which can be subdivided into two characters of "media retrieval entrance" and "meta data layer". Among them, the media retrieval entry layer integrates a multimedia model logic integration method for isomorphic systems. The common point of the integration methods of the two sub layers is that the integration of the media model itself does not establish the resource base, but accepts the user's request by the agent, converts the query request to the query language, through middleware technology and retrieval module, the retrieval method of multicultural media information model is carried out. The search request is sent out, and the result returned by each model is processed to the user at the same interface (Sawani, 2014). In this paper, the model of metadata integration is adopted, and the information resources among multicultural media are integrated through openurl technology.

\section{The integration of the performance layer}

The performance layer is the highest layer. The multicultural media integration model is also a logical integration method. It integrates various media applications in the network's space of public opinion, establishes multicultural media information navigation and media portal, and provides integrated services for users. The integration of multicultural media model is relatively simple, and the result of integration is clear. It is easy to get a general view of the multicultural media integration model system in the network's space of public opinion (Park, 2014).

\section{Experimental analysis}

\section{Model practicality analysis}

Supplementary data 2 (Wang; Dong, 2020) shows the integration model, integration objects, integration results, integration methods, and main technical conditions at different layers. It can be seen from the data layer that this model can establish the relevance of the media information resources in the data layer. In the Metadata layer, the semantic association among the Metadata can be obtained with the concept of "ontology mapping", and the control of the retrieved vocabulary can be extended in the retrieval entrance layer (Jung, 2016). In the performance layer, lexical control can be used as a basis for resource organization and association in the multicultural media integration model (Jung, 2015). Most of the traditional meta-database integration models integrate multicultural 
media databases from a single level, which can no longer meet the current actual needs (Colicpeisker; Mikola; Dekker, 2016).

According to the characteristics of the integration method of multicultural media in the above network's space of public opinion and the present situation of its construction, the results of this model are compared with the traditional Meta database multimedia integration model. The results of this model are shown in Supplementary data 3 (Wang; Dong, 2020).

When integrating the practice of multicultural media information in the network's space of public opinion, we must select suitable integration models according to the characteristics of media information integration. The experimental results show that compared with the Meta Database Multimedia integration model, this model has more advantages and more practicality to integrate the multicultural media information in the network's spaces of public opinion.

\section{Model integration's time analysis}

In order to compare the multicultural media integration model with the traditional Warehouse integration model and the Meta database integration model, the Massive Open Online Courses (MOOC) s'large data integration time under the three models is compared under different time conditions (Figure 3).

An analysis of Figure 3 shows that, in the same period, the time of using this integrated model to integrate MOOC large data is far lower than the traditional Warehouse integration model and the Meta database integration model. As times passes by, the traditional multimedia integration model based on Meta database takes a great time to integrate MOOC large data. The increase of this integration model is low, and it can be kept in a certain time range, which validates the absolute advantage of the integrated model in the integration time.

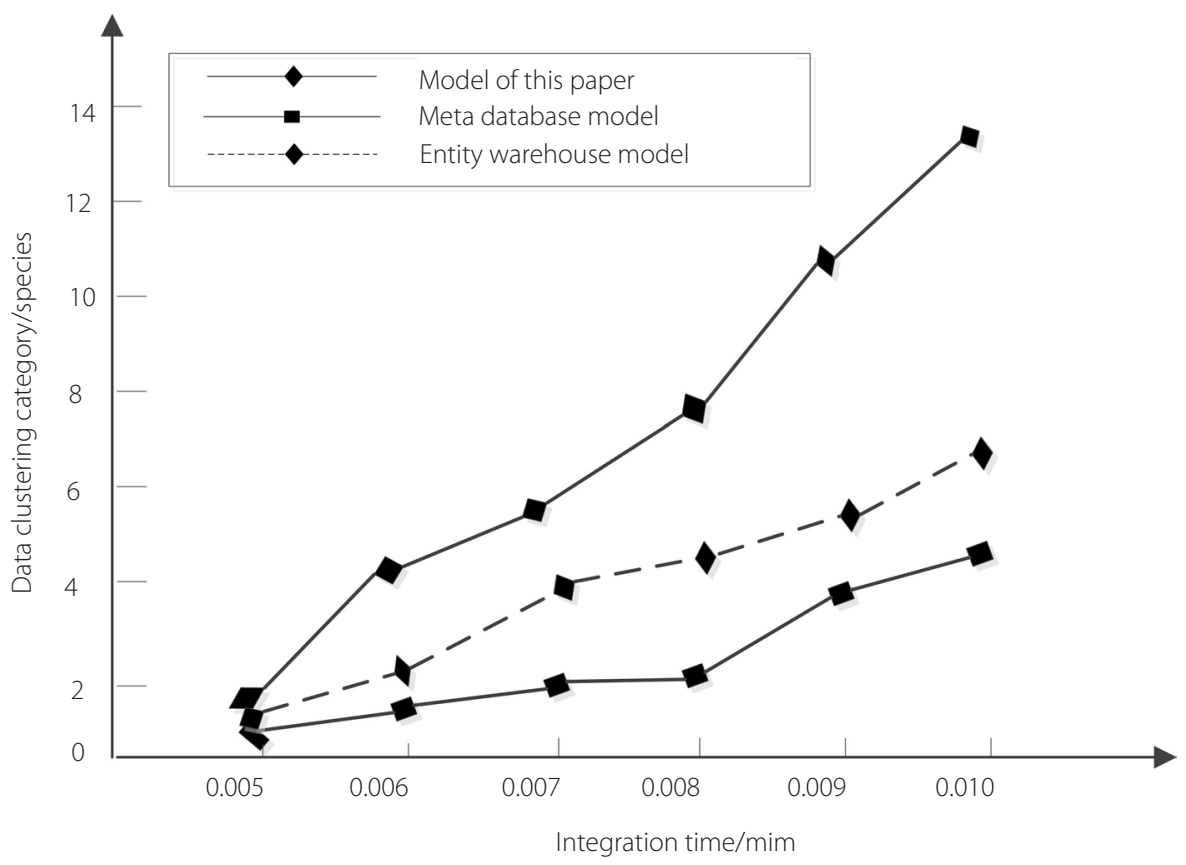

Figure 3. Comparison of three data integration models based on big data integration time.

Source: Elaborated by authors (2019). 


\section{Model stability analysis}

In order to further verify the performance of this multicultural media integration model, the traditional Warehouse integration model and the Meta database integration model are used as control. The integration stability of the three media integration models under the MOOC data is compared. The experiment has set up 40TB of data resources to be integrated and tested by CBKAL Software (Figure 4A).

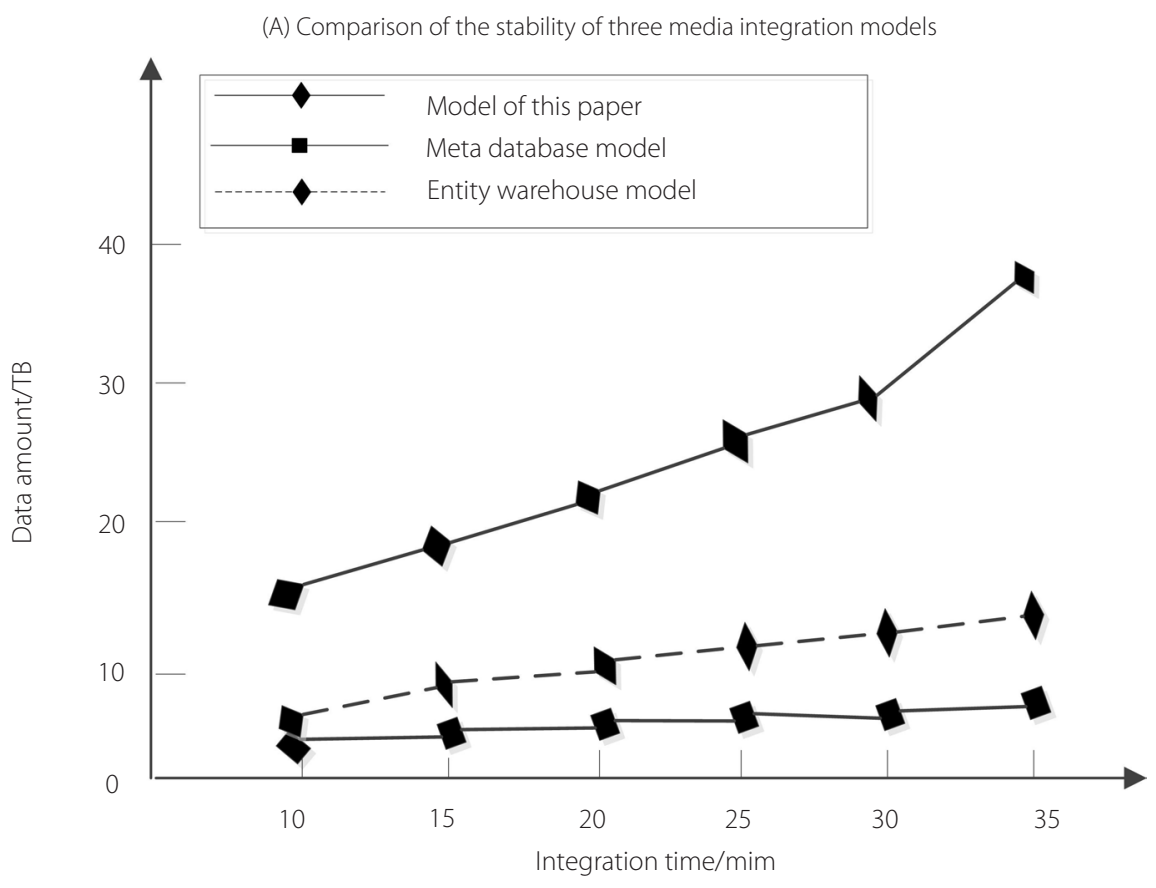

(B) Frequency comparison of three media integration models

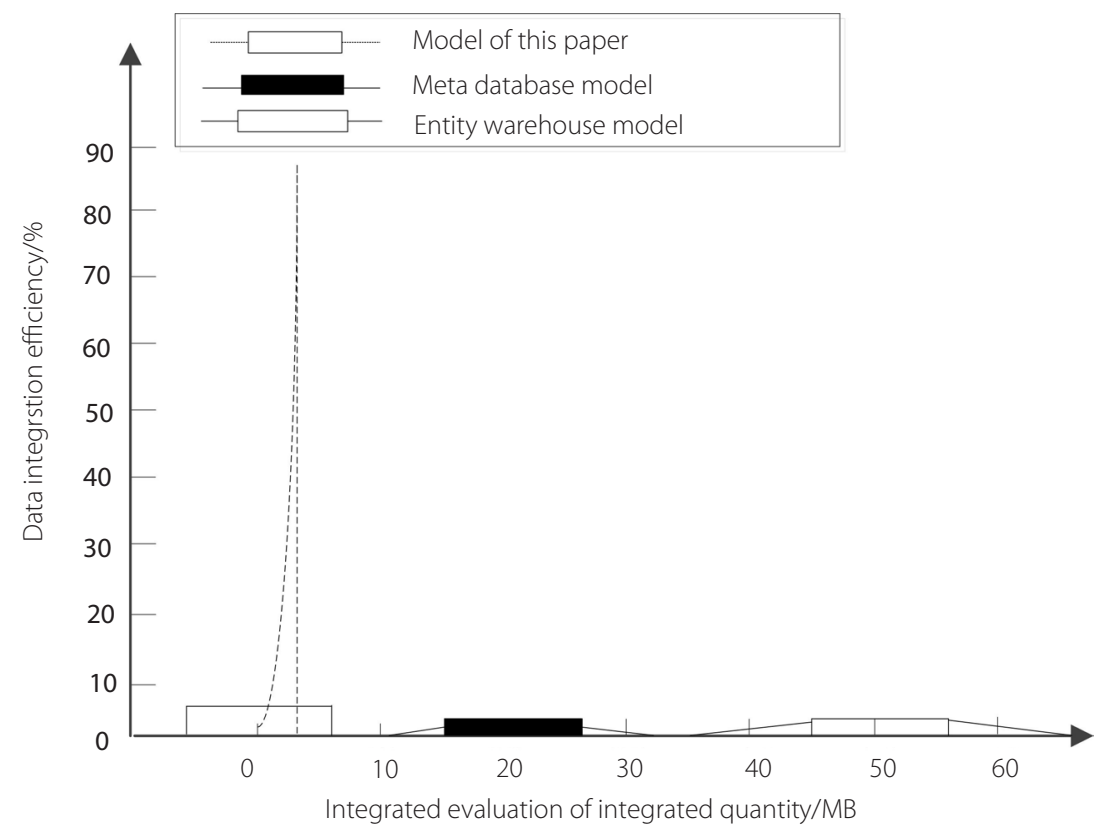

Figure 4. Comparison of three media integration models.

Source: Elaborated by authors (2019). 
According to Figure 4(A), the 35-minute integration process of multicultural media data, under the same time period, shows far greater stability of integration than that of the traditional entity Warehouse integration model and the Meta database integration model. With the passage of time, the model is integrated with large media data. Stability has increased with time, and the stability of traditional entity Warehouse integration model and the Meta database integration model has been very low, which validates the absolute advantage of the integration stability of this diversified media integration model (Jung 2016).

\section{Model frequency analysis}

In order to verify the advantages of this model in the multicultural media integration model frequency, the traditional Warehouse integration model and the Meta database integration model are used as control to compare the large data integration frequency of the three models (Figure 4B).

Figure 4(B) shows that the integration frequency of the large data in the multicultural media in the network's space of public opinion is 9 times that of the traditional entity Warehouse integration model and the Meta database integration model with the same amount of data, which further verifies that the integration mode of this paper has a high integration frequency advantage.

\section{Analysis of integration accuracy}

In order to verify the advantages of this model in the integration precision of multicultural media model, the traditional entity Warehouse integration model and the Meta database integration model are used as control to compare the large data integration accuracy of the media in the three models, as shown in Supplementary data 4 (Wang; Dong, 2020).

The analysis of Supplementary data 4 shows that, with the same amount of data, the accuracy of this model is much higher than that of the traditional Meta database model and the Warehouse model. At the

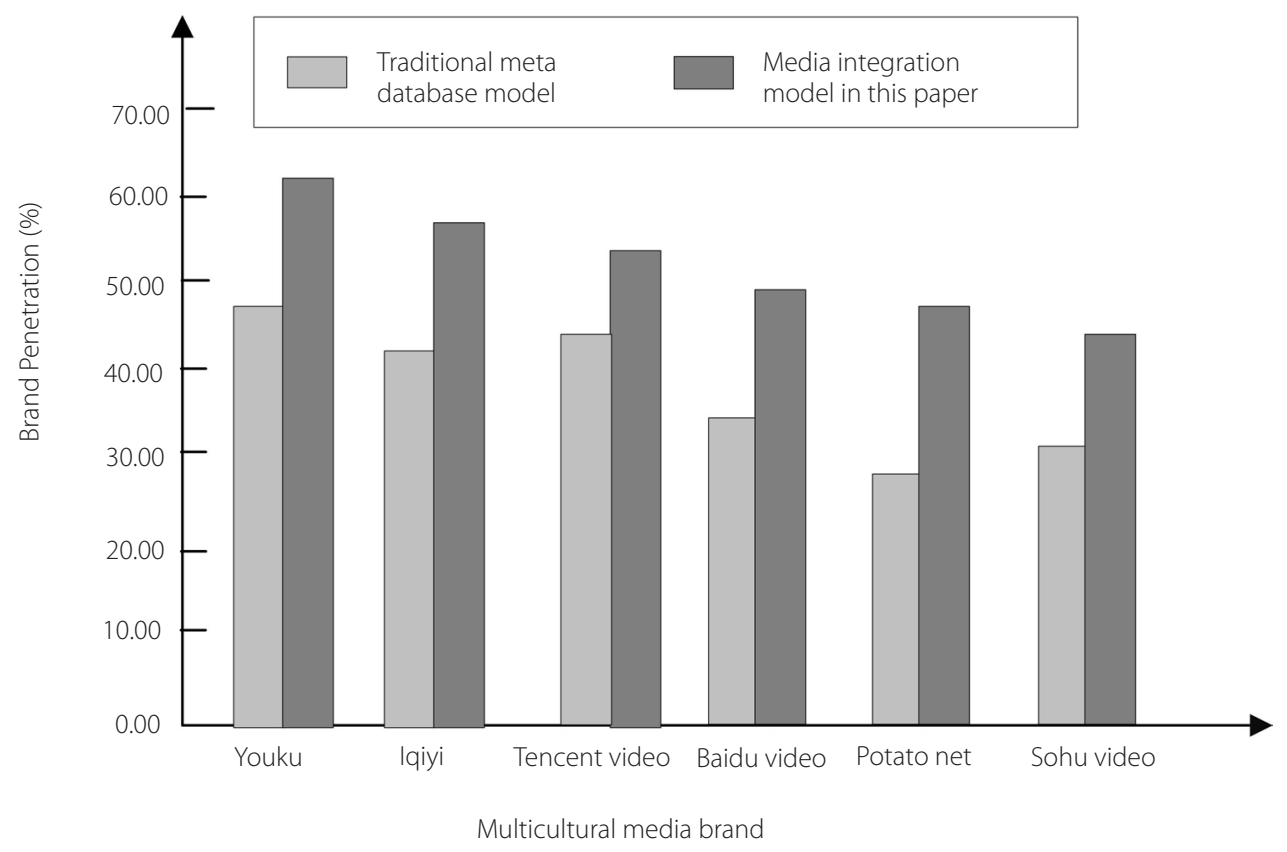

Figure 5. Comparison of the brand penetration of the multicultural media integration model with the traditional Meta database integration model.

Source: Elaborated by authors (2019). 
same time, the integration model error is controlled in a certain range while ensuring high precision. It verifies the absolute superiority of this model in terms of the accuracy of information integration in multicultural media.

The comprehensive performance of the multicultural media integration model in large data conditions is higher, which improves the problem of long times, low efficiency, and poor precision in the integration of the traditional Warehouse integration model and the Meta database integration model, improves the multicultural media information in the network's space of public opinion, and improves the timeliness of multimedia data integration in these spaces (Veronis; Ahmed, 2015).

\section{Comparison of the model brand permeability}

By using the integration model of multicultural media along with the traditional Warehouse integration model and the Meta database integration model, we integrate the existing multicultural media brand information in China and compare the brand permeability for different models (Figure 5).

As can be seen in Figure 5, compared with the traditional Warehouse integration model and the Meta database integration model, the integration of multicultural media information in the network's public spaces of opinion using the proposed model can improve the permeability of different brand media.

\section{Conclusion}

In order to solve the problems of poor logic, long integration time, and low accuracy of multimedia information integration, to improve the coordination of multicultural media information integration in distributed heterogeneous networks and carry out the intelligent integration of multicultural media information, we proposed and constructed a multicultural media integration model based on multi-agent cooperation. By comparing the multicultural media integration model with the traditional physical Warehouse Integration Model and the meta database integration model, the results show that the brand penetration rate can be improved by changing the method. Therefore, a correct understanding of the characteristics and forms of multicultural media, combined with the corresponding multicultural media policies, multicultural laws and multicultural inclusion mechanism, will be able to improve the brand penetration, to adapt to the global diversity, so as to enter a harmonious cultural environment and a period of construction of benign network public spaces of opinion.

\section{Contributors}

L. WANG and C. DONG has jointly carried out field work, method design, conclusion extraction, review, writing and follow-up work.

\section{References}

Ahmed, R.; Veronis, L. Multicultural media use and immigrant settlement: a comparative study of four communities in Ottawa, Canada. Journal of International Migration and Integration, v. 18, n. 2, p. 1-26, 2016. Doi: https://doi.org/ 10.1007/s12134-016-0488-7.

Ahmed, R; Veronis, L. Multicultural media use and immigrant settlement: A comparative study of four communities in Ottawa, Canada. Journal of International Migration and Integration, v. 18, n. 2, p. 587-612, 2017. https://doi.org/10. 1007/s12134-016-0488-7.
Barzilay, O.; Urquhart, C. Understanding reuse of software examples: a case study of prejudice in a community of practice. Information and Software Technology, v. 56, n. 12, p. 1613-1628, 2014. Doi: https://doi.org/10.1016/j.infsof.2014.02.013.

Bolstad, J. Dynamics of European integration: public opinion in the core and periphery. European Union Politics, v. 16, n. 1, p. 23-44, 2016. Doi: https://doi.org/10.1177/1465116514551303.

Colicpeisker, V.; Mikola, M.; Dekker, K. A multicultural nation and its (Muslim) other? Political leadership and media reporting in 
the wake of the 'Sydney Siege.' Journal of Intercultural Studies, v. 37, n. 4, p. 373-389, 2016. Doi: https://doi.org/10.1080/0725 6868.2016.1190693.

Deutschmann, E.; Minkus, L. Swinging Leftward: public opinion on economic and political integration in Latin America, 1997-2010. Latin American Research Review, v. 53, n. 1, p. 38-56, 2018. Doi: https://doi.org/10.25222/larr.250.

Fleras, A. Multicultural media in a post-multicultural Canada? Rethinking integration. Global Media Journal Canadian Edition, v. 8, n. 2, p. 25-47, 2015. Doi: https://doaj.org/ article/075b09a35d3d414a9699c8ded6c3a14f.

Guo, J. et al. Measurement framework for assessing disruptive innovations. Technological Forecasting and Social Change, v. 139, p. 250-265, 2019. Doi: https://doi.org/10.1016/j. techfore.2018.10.015.

He, Y. B. et al. Image quality enhanced recognition of laser cavity based on improved random hough transform. Journal of Visual Communication and Image Representation, v. 69, n. 11, e102679, 2019. Doi: https://doi.org/10.1016/j. jvcir.2019.102679.

Hooghe, M.; Vroome, T. D. How does the majority public react to multiculturalist policies? A comparative analysis of European countries. American Behavioral Scientists, v. 59, n. 6, p. 7 47-768, 2015. Doi: https://doi.org/10.1177/0002764214566499.

Hwang, M. C. The effect of multicultural family support service: examining integration with immigrant wives in South Korea. Journal of Social Service Research, v. 42, n. 5, p. 1-21, 2016. Doi: https://doi.org/10.1080/01488376.2016.1216917.

Jara-Ibarra, C. Public support for Latin American integration: an econometric model for the assessment of individual and contextual factors. Estudios Internacionales, v. 46, n. 179, p. 35-60, 2014. Doi: https://doi.org/10.5354/0719-3769.2014.35467.

Jung, G. Debating multicultural Korea: media discourse on migrants and minorities in South Korea. Journal of Ethnic and Migration Studies, v. 41, n. 6, p. 985-1013, 2015. Doi: https://doi. org/10.1080/1369183X.2014.1002202.

Jung, Y. B. A study on the status analysis and development direction of multicultural media education: focusing on an in-depth interview with managers of region multicultural media education in Jeju. Journal of Communication Science, v. 16, n. 4, p. 287-334, 2016. Doi: https://doi.org/10.14696/ jcs.2016.12.16.4.287.

Lauridsen, K. M. IntIUni: the opportunities and challenges of the multilingual and multicultural learning space in the international university. European Journal of Applied Linguistics, v. 4, n. 2, p. 349-354, 2016. Doi: https://doi.org/10.1515/ eujal-2016-0010.

Liu, Y.; Zhao, Q. E-voting scheme using secret sharing and K-anonymity. World Wide Web-Internet and Web Information Systems, v.22, p. 1657-1667,2019. Doi: https://doi.org/10.1007/ s11280-018-0575-0.

Park, K. Foreigners or multicultural citizens? Press media's construction of immigrants in South Korea. Ethnic and Racial Studies, v. 37, n. 9, p. 1565-1586, 2014. Doi: https://doi.org/10. 1080/01419870.2012.758860

Sawani, Y. M. Arabs and democracy: an analysis of the findings of the survey of Arab public opinion towards democracy. Contemporary Arab Affairs, v. 7, n. 3, p. 351-362, 2014. Doi: https://doi.org/10.1080/17550912.2014.935597.

Sun, G. et al. An adaptive differential evolution with combined strategy for global numerical optimization. Soft Computing, v. 24, p. 6277-6296, 2020. Doi: https://doi.org/10.1007/s00500019-03934-3.

Sun, G.; Xu, G.; Jiang, N. A simple differential evolution with time-varying strategy for continuous optimization. Soft Computing, n. 3, 2019. Doi: https://doi.org/10.1007/s00500019-04159-0.

Titley, G. After the end of multiculturalism: public service media and integrationist imaginaries for the governance of difference. Global Media and Communication, v. 10, n. 3, p. 247260, 2014. Doi: https://doi.org/10.1177/1742766514552351.

Vazquez, L. A. Integration of multicultural and psychoanalytic concepts: a review of three case examples with women of color. Psychoanalytic Psychology, v. 31, n. 3, p. 435-448, 2014.

Veronis, L.; Ahmed, R. The role of multicultural media in connecting municipal governments with ethnocultural and immigrant communities: the case of Ottawa. Global Media Journal Canadian Edition, v. 8, v. 2, p. 73-95, 2015.

Wang, L.; Dong, C. Analysis of the model of integration of multicultural media in the network's space of public opinion [Data set]. Zenodo, 2020. Doi: http://doi.org/10.5281/ zenodo.4263538.

Zeng, H. B. et al. Sampled-data stabilization of chaotic systems based on a t-s fuzzy model. Information Sciences, v. 46, n. 1 , p. 72-88, 2019. Doi: https://doi.org/10.1016/j.ins.2019.01.046.

Zhang, $H$. et al. Research on the information dissemination mechanisms of weibo in scale-free networks. Physica A: Statistical Mechanics and its Applications, v. 532, p. 121877, 2019. Doi: https://doi.org/10.1016/j.physa.2019.121877. 